\title{
International Conference on Marine Simulation
}

\section{8}

The Southampton School of Navigation and the National Maritime Institute, in association with the Royal Institution of Naval Architects, the Nautical Institute and the Royal Institute of Navigation, are organizing a Conference to be held at the Southampton School of Navigation, Warsash on 5, 6 and 7 September 1978 . The theme of the Conference is the use of simulators for training and research in the shipping industry and papers are invited on the following topics: the assessment of training needs, the design and construction of simulators, their use and effectiveness for training and research, the qualifications and training of simulator staff. Although the main emphasis will be on navigational and bridge simulators it is hoped that material on other marine simulators will be offered, e.g. engine room or cargo control simulators. Priority will be given to papers describing actual experience with simulators in commercial applications. Abstracts of suggested papers (not more than 500 words) should be sent as soon as possible to: I. Millar, National Maritime Institute, Feltham, Middlesex, from whom further details of the Conference may be obtained. 